\title{
Detection of ULF electromagnetic emissions as a precursor to two earthquakes in China*
}

\author{
Qi $\mathrm{Li}^{1, \star}$ Peiyu Zhu ${ }^{2}$ Alimjan Mamatemin ${ }^{3}$ and Xuegong $\mathrm{Xu}^{4}$ \\ ${ }^{1}$ Institute of Geophysics, China Earthquake Administration, Beijing 100081, China \\ ${ }^{2}$ Chongming Observatory, Earthquake Administration of Shanghai Municipality, Shanghai 202164, China \\ ${ }^{3}$ Kashi Observatory, Earthquake Administration of Xinjiang Uygur Autonomous Region, \\ Ürumuqi 844000, China \\ 4 Jinghai Observatory, Earthquake Administration of Tianjin Municipality, Tianjin 301600, China
}

\begin{abstract}
The geomagnetic data recorded by Kashi and Jinghai observatories in China were analyzed with improved polarization method. We compared the result around $0.01 \mathrm{~Hz}$ which is thought to be useful to detect the ULF anomaly with the result around $0.1 \mathrm{~Hz}$ which was inferred from the earthquake depth according to the skin effect, and found that $0.1 \mathrm{~Hz}$ is more proper to detect the ULF anomaly for both earthquakes studied in this paper.
\end{abstract}

Key words: ULF anomaly; geomagnetic data; polarization analysis; earthquake precursor CLC number: P315.72+1 Document code: A

\section{Introduction}

Electromagnetic phenomena in a wide frequency range have been recognized as precursors to earthquakes. The ULF (ultra low frequency, with frequency less than $10 \mathrm{~Hz}$ ) frequency range is especially promising because of several reported convincing evidences for large earthquakes such as Spitak earthquake (Kopytenko et al., 1993), Loma Prieta earthquake (FraserSmith et al., 1990) and Guam earthquake (Hayakawa et al., 1996). Hattori (2004) empirically summarized the morphological features of ULF emissions associated with large earthquakes: (1) The intensity is not so large and the most useful frequency is just around $0.01 \mathrm{~Hz}$ (period $T=100 \mathrm{~s}$ ). (2) The first enhancemen$\mathrm{t}$ or peak appears about one week to one month before earthquake, and then their level calms down just before earthquake occurs. (3) Pre-seismic ULF emissions would be detected for $M \geq 4.5$ earthquakes which roughly satisfy $0.025 R<M-4.5$, where $R$ is epicentral distance.

\footnotetext{
* Received 15 June 2011; accepted in revised form 1 November 2011; published 10 December 2011.

* Corresponding author. e-mail: darcyli@163.com

(c) The Seismological Society of China and Springer-Verlag Berlin Heidelberg 2011
}

The key problem regarding these seismogenic ULF emissions is how to detect and identify weak signals from strong geomagnetic background field. Hayakawa et al. (1996) used the polarization analysis to distinguish the seismogenic ULF emissions from other noises. Ida et al. (2008) improved the polarization analysis. Gotoh et al. (2002) found that principal component analysis is effective in distinguishing the seismogenic emissions from many kinds of mixed ULF emissions (geomagnetic variation, man-made noise and seismogenic emission).

In this paper we applied the improved polarization analysis to the ULF data observed in China and tried to find out any significant precursory effect for both earthquakes (Kashi earthquake and Wenan earthquake) in China and compared the results of different frequencies.

\section{ULF geomagnetic data and earthquakes}

Kashi observatory is located in northwest of China, and Jinghai observatory is located in north of China. Three geomagnetic components ( $H$ : NS component, $D$ : EW component, and $Z$ : vertical component) were observed at both observatories. GM-3 fluxgate magne- 
tometer made in China was installed in Kashi observatory and the other fluxgate magnetometer made in UCLA (University of California, Los Angeles) from SMALL (Sino-Magnetic Array at Low Latitudes) project was installed in Jinghai observatory. The sampling rate of both magnetometers is $1 \mathrm{~Hz}$. Both GM-3 and UCLA fluxgate magnetometers were widely installed in China, and the data derived from them were proved to be reliable and stable (Han et al., 2000).

Nearly four years data from 1 March 2003 to 31 December 2006 are used for the analysis of Kashi. Two rather large earthquakes (both with magnitude $M_{S} 5.9$ ) were observed near the Kashi observatory during the above time span; one earthquake on 12 March, 2003 and the other on 2 September, 2003. The distance from the former earthquake to Kashi observatory is about 120 $\mathrm{km}$, while the epicentral distance for the latter earthquake is about $137 \mathrm{~km}$. The focal depths of both earthquakes are $15 \mathrm{~km}$.

Because of too much missing data, only half year data from March 2006 to 31 August 2006 are used for the analysis in Jinghai. Wenan $M_{\mathrm{S}} 5.1$ earthquake on 4 July, 2006 occurred just $53 \mathrm{~km}$ away from Jinghai observatory, and the focal depth is $15 \mathrm{~km}$. No any other earthquake occurred during the above analyzed period within $300 \mathrm{~km}$ from Jinghai observatory.

\section{Polarization analysis}

Polarization analysis is to comput ratio of magnetic vertical to horizontal component $S_{\mathrm{Z}} / S_{\mathrm{H}}, S_{\mathrm{Z}} / S_{\mathrm{D}}$ or $S_{\mathrm{Z}} / S_{\mathrm{G}}$ (where $S_{\mathrm{Z}}, S_{\mathrm{H}}, S_{\mathrm{D}}$ and $S_{\mathrm{G}}$ indicate the spectral intensities of the vertical component, NS horizontal component, EW component and $S_{\mathrm{G}}^{2}+S_{\mathrm{D}}^{2}$, respectively). These ratios are expected to be relatively small for the plasma waves coming from the ionosphere/magnetosphere and increasing ( $\sim 1$ or even more) for seismogenic emissions.

Ida et al. (2008) improved the polarization analysis. In order to treat each field component equally, each geomagnetic field component is standardized. The standardized field component is defined by

$$
E_{i}=\frac{X_{i}-\mu_{i}}{\sigma_{i}}
$$

where $X_{i}$ is the average value for one day for the $i$ component ( $i=Z, H, D$ and $G$, respectively), $\mu_{i}$ is the average of the component $i$ over the whole period, and $\sigma_{i}$ is the standard deviation of the same component $i$ over the whole period. An increase in the polarization resulted either from increase in $Z$ or from a decrease in $H$ or $D$, or from both cases. Thus, only when the standardized values of components exceed 0.1 (that is, rather significant change is observed), the polarization and the corresponding result are computed.

\section{Signal processing}

We used the skin effect of electromagnetic wave to get the possible frequency originating from the sources of these earthquakes. The skin depth is defined by

$$
\delta=\left[\frac{2 \rho}{\mu \omega}\right]^{\frac{1}{2}},
$$

where $\delta$ is the skin depth, $\rho$ is the resistivity, $\mu$ is the magnetic permeability, $\omega$ is the angular frequency. The focal depths of the above mentioned earthquakes are both $15 \mathrm{~km}$, so we defined $\delta=15 \mathrm{~km}$. Besides, we defined $\mu=\mu_{0}=4 \pi \times 10^{7}$ (Henries/meter), where $\mu_{0}$ is the permeability of vacuum. Because we could not find the specific resistivities around the epicenters of these earthquakes, we defined $\rho=100 \Omega \cdot \mathrm{m}$, that is the resistivity for sedimentary rock. Finally, the calculation indicated that $0.09 \mathrm{~Hz}$ was the possible frequency related to the sources of these earthquakes. Considering uncertainty of resistivities, we actually analyzed the polarization ratio in frequency band $0.05-0.15 \mathrm{~Hz}$.

According to previous study (Hattori, 2004; Hayakawa et al., 2007), the geomagnetic signals at the frequency around $0.01 \mathrm{~Hz}$ are thought to be sensitive to seismic activities. So we also analyzed the polarization ratio in frequency band $0.007-0.013 \mathrm{~Hz}$. The procedure of signal processing is as follows. Firstly, the time series of geomagnetic field data were transferred into the frequency domain by FFT; secondly, we picked up the data at the frequency around $0.1 \mathrm{~Hz}(0.05-0.15 \mathrm{~Hz})$ and 0.01 $\mathrm{Hz}(0.007-0.013 \mathrm{~Hz})$ for Kashi and Jinghai observatories from the FFT result, respectively. Analysis of the geomagnetic diurnal variation has revealed that more artificial noises was included at daytime than that at nighttime (Li et al., 2011), therefore we calculated the average of each geomagnetic component $(Z, H, D$ and $G$ ) during 23:00:00LT-01:59:59LT (local midnight) in order to reduce artificial effects; thirdly, the standardized values of $S_{\mathrm{Z}}, S_{\mathrm{H}}, S_{\mathrm{D}}, S_{\mathrm{G}}$ are calculated, and then the final improved polarization result could be derived.

\section{Experimental results}

\subsection{Result for Kashi earthquakes}

Figure 1 shows the temporal variation of Dst index and the spectral intensities $S_{\mathrm{H}}, S_{\mathrm{D}}, S_{\mathrm{G}}, S_{\mathrm{Z}}$ at the frequency around $0.1 \mathrm{~Hz}$ for Kashi observatory from March 


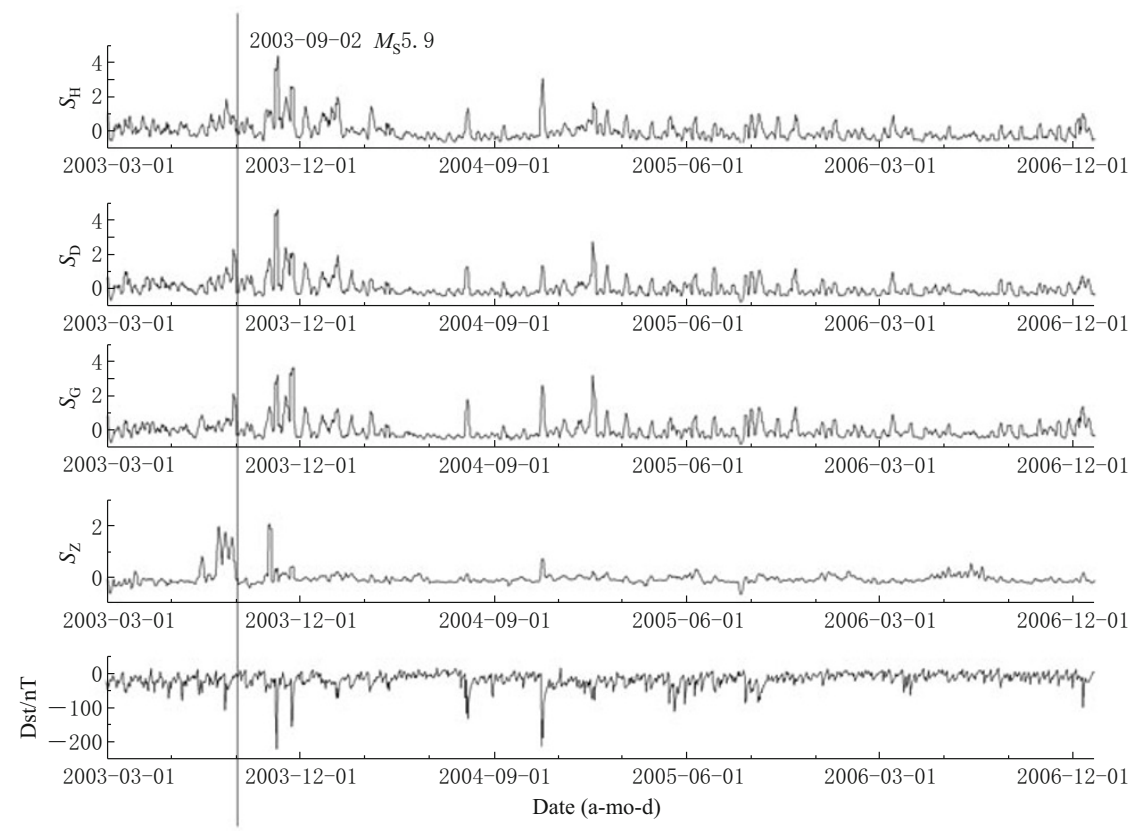

Figure 1 Temporal variation of Dst index and the spectral intensities $S_{\mathrm{H}}, S_{\mathrm{D}}, S_{\mathrm{G}}, S_{\mathrm{Z}}$ at the frequency around $0.1 \mathrm{~Hz}$ for Kashi observatory from March 2003 to December 2006. Five days running means of $S_{\mathrm{H}}$, $S_{\mathrm{D}}, S_{\mathrm{G}}$ and $S_{\mathrm{Z}}$ were used in the plot. The vertical line indicates the earthquake occurrence date.

2003 to December, 2006. Five days running means of $S_{\mathrm{H}}, S_{\mathrm{D}}, S_{\mathrm{G}}$ and $S_{\mathrm{Z}}$ were used in the plot. The vertical line in Figure 1 indicates the occurrence date of the nearby earthquake on 2 September, 2003. It can be seen from Figure 1 that the variations of the spectral intensities $S_{\mathrm{H}}, S_{\mathrm{D}}$ and $S_{\mathrm{G}}$ are in accordance with that of Dst index in general, the correlation coefficients between them were calculated. The correlation coefficient is defined by

$$
r_{x y}=\frac{\sum_{i=1}^{n}\left(x_{i}-\bar{x}\right)\left(y_{i}-\bar{y}\right)}{\sqrt{\sum_{i=1}^{n}\left(x_{i}-\bar{x}\right)^{2}} \sqrt{\sum_{i=1}^{n}\left(y_{i}-\bar{y}\right)^{2}}},
$$

where $r_{x y}$ is the correlation coefficient, $n$ is number of values or elements, $x$ is the first score, $y$ is the second score, $\bar{x}$ is the average value of $x, \bar{y}$ is the average value of $y$. Calculated from the above formula, the correlation coefficients between Dst index and $S_{\mathrm{H}}, S_{\mathrm{D}}, S_{\mathrm{G}}$ are $-0.57,-0.54$ and -0.58 , respectively. Figure 2 also shows the relationship between them, and $S_{\mathrm{H}}, S_{\mathrm{D}}$ and $S_{\mathrm{G}}$ are strengthened with decrease of the Dst. Tested by the critical values of the correlation coefficient, there is relationship between Dst index and $S_{\mathrm{H}}, S_{\mathrm{D}}, S_{\mathrm{G}}$, which means that the variation of $S_{\mathrm{H}}, S_{\mathrm{D}}, S_{\mathrm{G}}$ are related to the activities of ionosphere/magnetosphere currents. The correlation coefficient between Dst index and $S_{\mathrm{Z}}$ is -0.23 , and much smaller than those between Dst and $S_{\mathrm{H}}, S_{\mathrm{D}}, S_{\mathrm{G}}$, which indicates that $S_{\mathrm{Z}}$ includes electromagnetic emission not only from ionosphere/magnetosphere source but also from underground source. It is also found from Figure 1 that there is an enhancement of $S_{\mathrm{Z}}$ almost one month before the earthquake on 2 September, 2003.

The relationship between Dst and $S_{\mathrm{H}}, S_{\mathrm{D}}, S_{\mathrm{G}}, S_{\mathrm{Z}}$ is similar to Figure 1 for remaining cases in this paper, so we did not show the temporal variation of spectral intensities for other cases.

Figure 3 shows the temporal variation of Dst index and improved polarization results for Kashi observatory from March 2003 to December 2006. Five days running means of absolute values of $S_{\mathrm{Z}} / S_{\mathrm{H}}, S_{\mathrm{Z}} / S_{\mathrm{D}}$ and $S_{\mathrm{Z}} / S_{\mathrm{G}}$ were used in the plot. It is found from Figure 3 that the variations of polarization result $S_{\mathrm{Z}} / S_{\mathrm{H}}, S_{\mathrm{Z}} / S_{\mathrm{D}}$ and $S_{\mathrm{Z}} / S_{\mathrm{G}}$ are not in accordance with that of Dst index. The correlation coefficients between Dst and $S_{\mathrm{Z}} / S_{\mathrm{H}}, S_{\mathrm{Z}} / S_{\mathrm{D}}$, $S_{\mathrm{Z}} / S_{\mathrm{G}}$ are $0,-0.01$ and -0.07 , respectively. The scatter diagram in Figure 4 clearly shows no relationship between them. Concentrated significant enhancement is observed before the earthquake on September 2, 2003, and the peak amplitude is far more than three times of variance during the whole period.

No enhancement of polarization result is observed before another Kashi earthquake on 12 March, 2003 in Figure 3. Because the original data began from 1 March, 

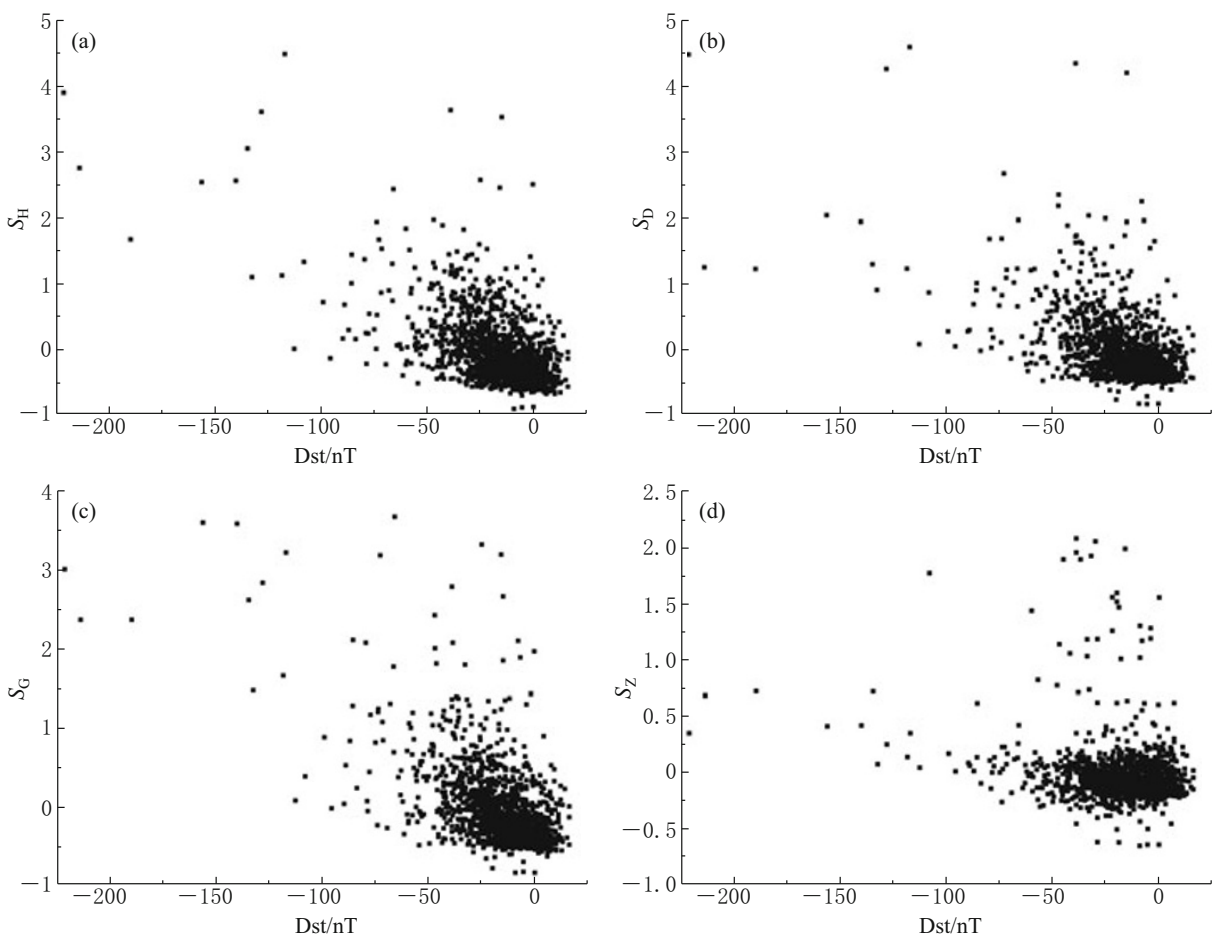

Figure 2 Scatter diagrams for $S_{\mathrm{H}}, S_{\mathrm{D}}, S_{\mathrm{G}}, S_{\mathrm{Z}}$ and Dst index. The correlation coefficients between five days running mean of $S_{\mathrm{H}}, S_{\mathrm{D}}, S_{\mathrm{G}}, S_{\mathrm{Z}}$ and Dst index are $-0.57,-0.54,-0.58$ and -0.23 , respectively.

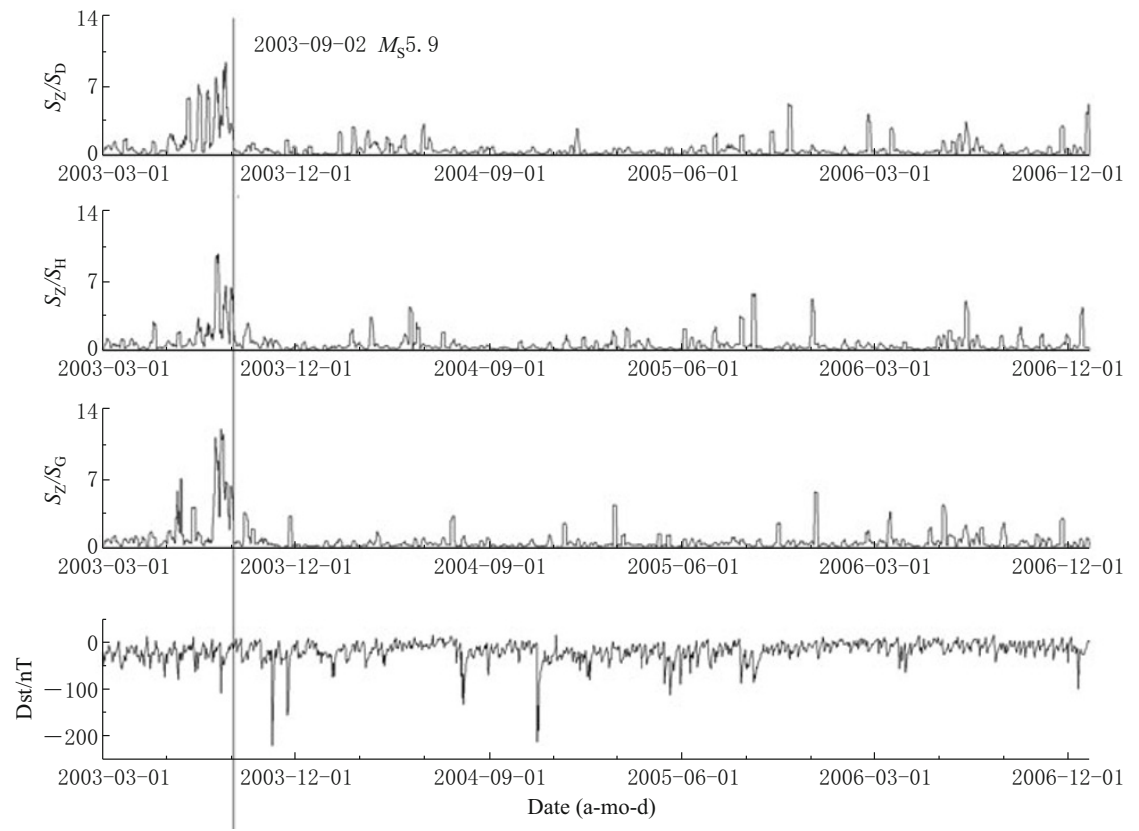

Figure 3 Temporal variation of Dst index and improved polarization results around $0.1 \mathrm{~Hz}$ for Kashi observatory from March 2003 to December 2006. Five days running means of absolute values of $S_{\mathrm{Z}} / S_{\mathrm{H}}$, $S_{\mathrm{Z}} / S_{\mathrm{D}}$ and $S_{\mathrm{Z}} / S_{\mathrm{G}}$ were used in the plot. The vertical line indicates the earthquake occurrence date. 

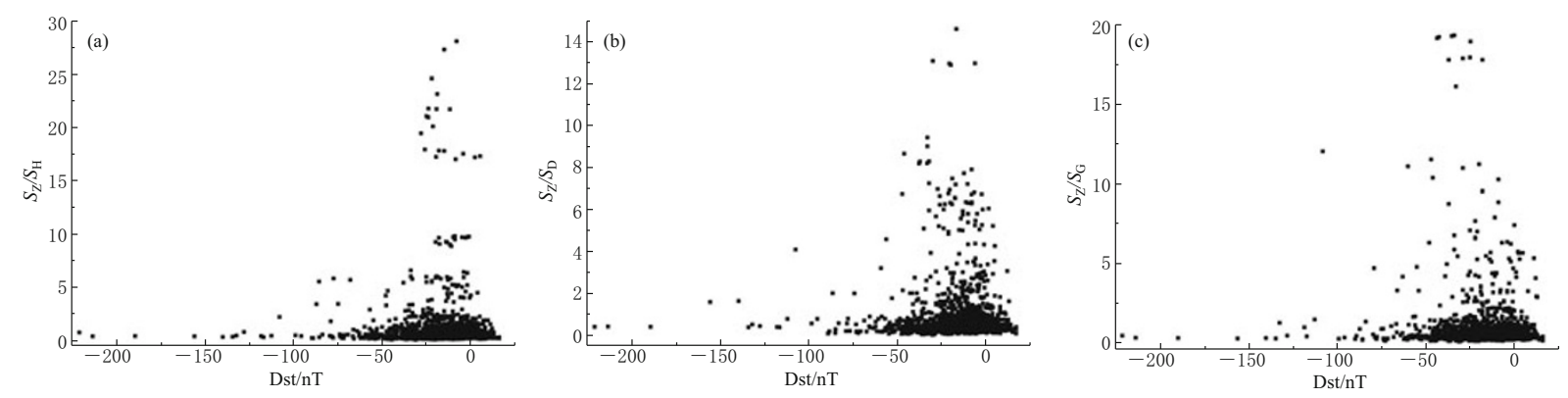

Figure 4 Scatter diagrams for $S_{\mathrm{Z}} / S_{\mathrm{H}}, S_{\mathrm{Z}} / S_{\mathrm{D}}, S_{\mathrm{Z}} / S_{\mathrm{G}}$ and Dst index. The correlation coefficients between five days running means of $S_{\mathrm{Z}} / S_{\mathrm{H}}, S_{\mathrm{Z}} / S_{\mathrm{D}}, S_{\mathrm{Z}} / S_{\mathrm{G}}$ and Dst index are $0,-0.01$ and -0.07 , respectively.

2003 , it is possible that the significant change appears before that.

Figure 5 shows the temporal variation of Dst index and improved polarization results around $0.01 \mathrm{~Hz}$ for Kashi observatory from March 2003 to December 2006. Five days running means of absolute values of $S_{\mathrm{Z}} / S_{\mathrm{H}}, S_{\mathrm{Z}} / S_{\mathrm{D}}$ and $S_{\mathrm{Z}} / S_{\mathrm{G}}$ were also used in the plot. The vertical line indicates the earthquake occurrence date. Concentrated significant enhancement is also observed before the earthquake on 2 September, 2003 in Figure 5. Besides, there is also significant enhancement appeared before April, 2003, but most of them appeared after the earthquake on 12 March, 2003, so it is not sure if the enhancement is related to the earthquake on 12 March, 2003.

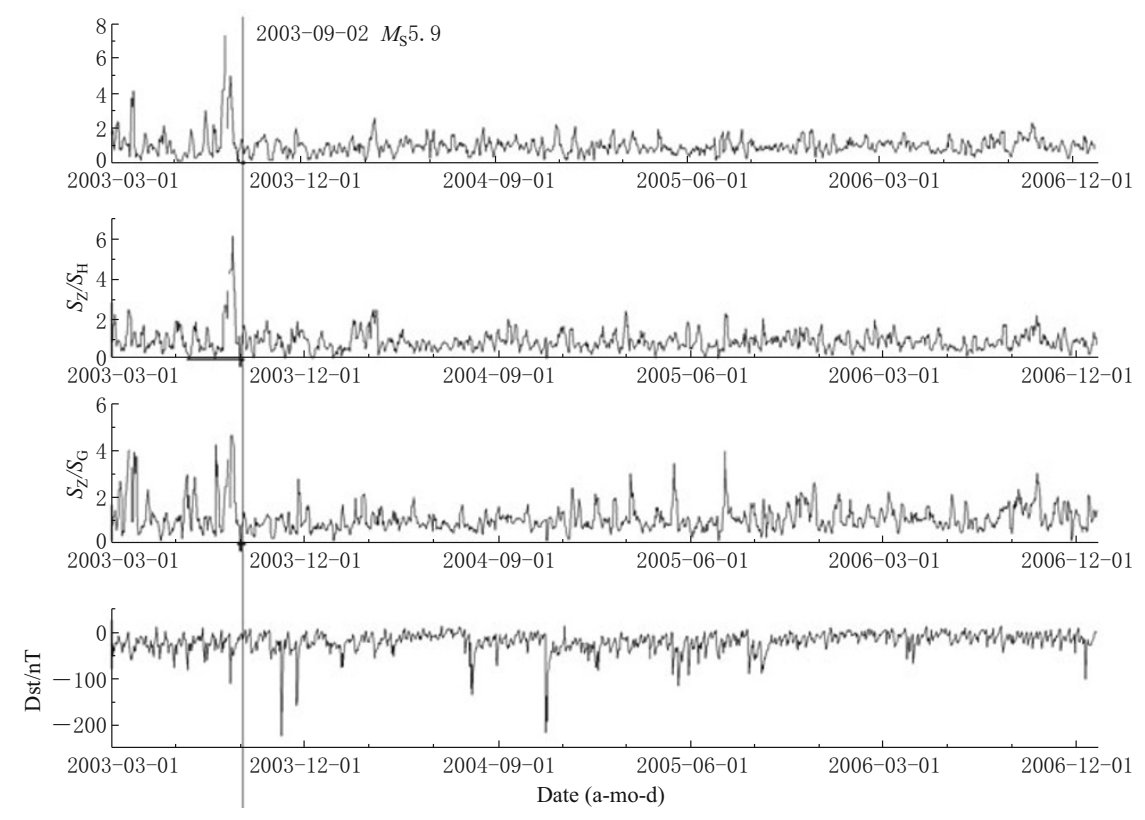

Figure 5 Temporal variation of Dst index and improved polarization results around $0.01 \mathrm{~Hz}$ for Kashi observatory from March 2003 to December 2006. Five days running means of absolute values of $S_{\mathrm{Z}} / S_{\mathrm{H}}$, $S_{\mathrm{Z}} / S_{\mathrm{D}}$ and $S_{\mathrm{Z}} / S_{\mathrm{G}}$ were used in the plot. The vertical line indicates the earthquake occurrence date.

\subsection{Result for Wenan earthquake}

Figure 6 shows the temporal variation of Dst index and improved polarization results around $0.1 \mathrm{~Hz}$ for Jinghai observatory from March 2006 to August 2006. Similar to the result for Kashi earthquake, it is found that the significant enhancement of polarization result is observed only before Wenan earthquake. The improved polarization results around $0.01 \mathrm{~Hz}$ was showed in Figure 7 . Although there is similar anomaly appeared before Wenan earthquake, there are several other significant enhancement appeared during the analyzed period. 


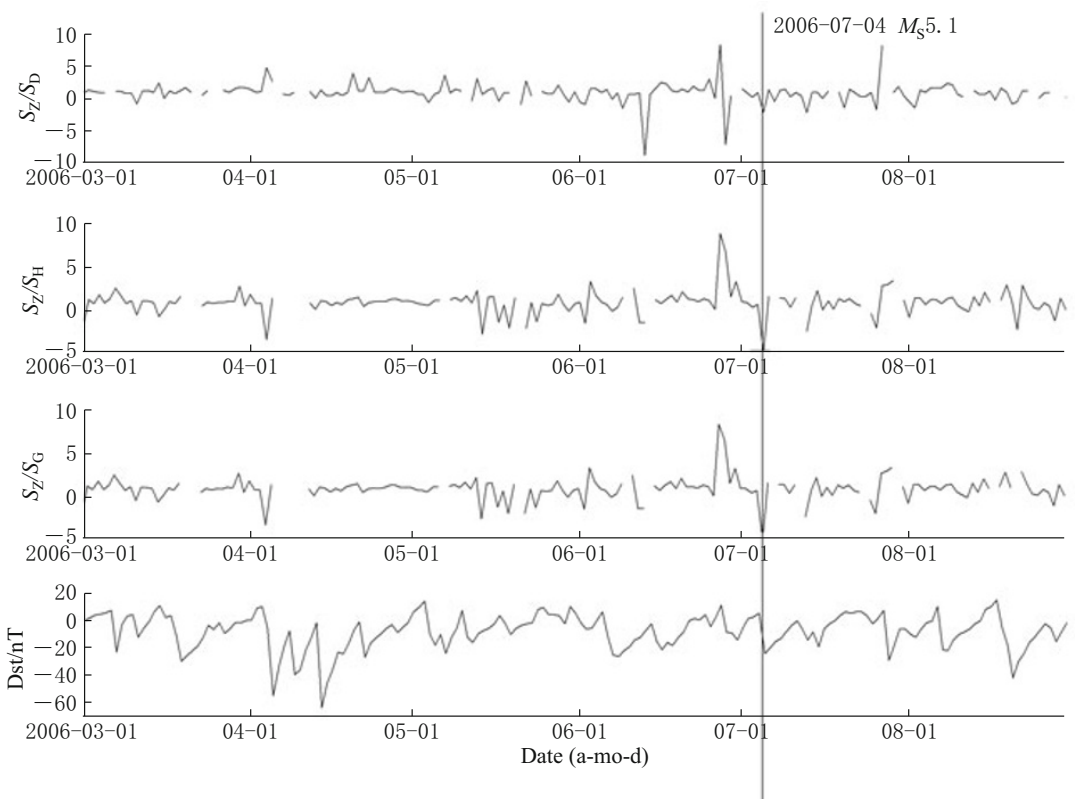

Figure 6 Temporal variation of Dst index and improved polarization results around $0.1 \mathrm{~Hz}$ for Jinghai observatory from March 2006 to August 2006. The vertical line indicates the earthquake occurrence date.
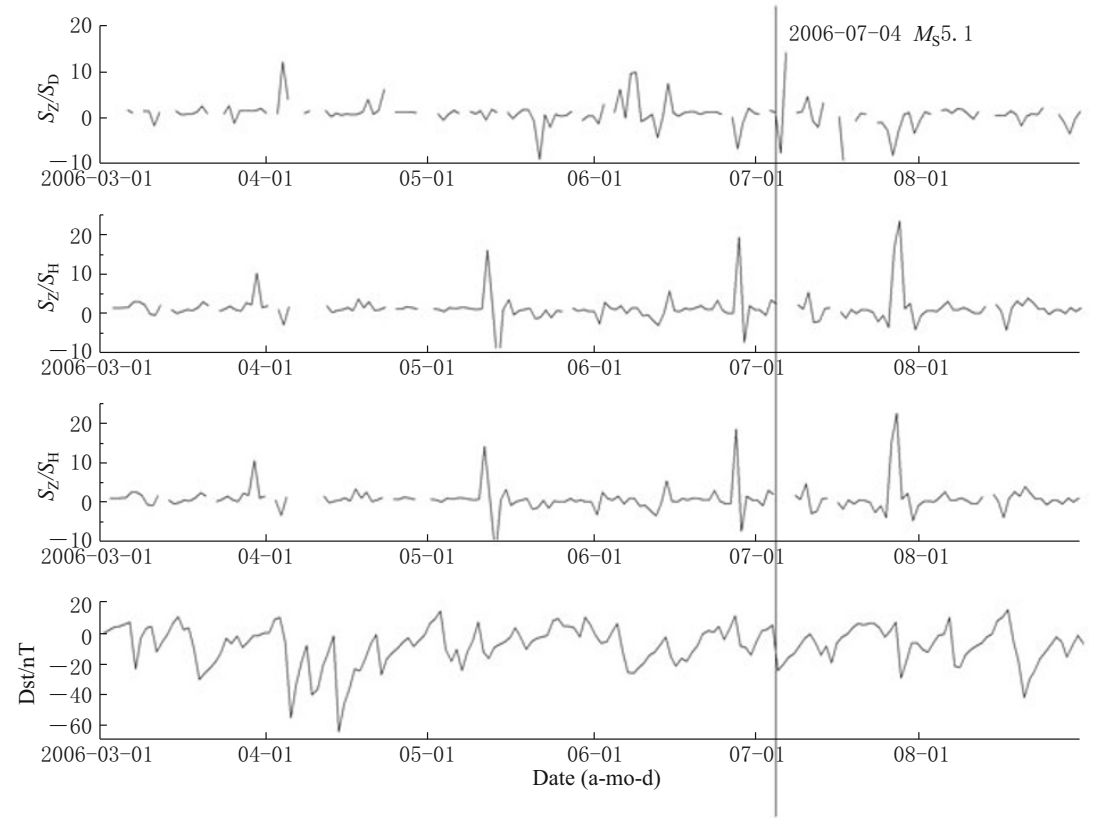

Figure 7 Temporal variation of Dst index and improved polarization results around $0.01 \mathrm{~Hz}$ for Jinghai observatory from March 2006 to August 2006. The vertical line indicates the earthquake occurrence date.

\section{Discussion and conclusions}

The correlation coefficients between five days running means of $S_{\mathrm{H}}, S_{\mathrm{D}}, S_{\mathrm{G}}, S_{\mathrm{Z}}$ and Dst index were compared. The correlation coefficient between Dst index and $S_{\mathrm{Z}}$ is much smaller than those between Dst and $S_{\mathrm{H}}$, $S_{\mathrm{D}}, S_{\mathrm{G}}$, which indicates that $S_{\mathrm{Z}}$ includes electromag- netic emission not only from ionosphere/magnetosphere source but also from underground source. As shown in Figure 1, the enhancement of $S_{Z}$ before Kashi earthquake prove that $\mathrm{Z}$ component include the information from epicenter during seismogenic process.

The improved polarization analysis was applied to the geomagnetic data recorded at Kashi and Jinghai ob- 
servatories of China in this paper. Significant enhancement of polarization result was found before nearby earthquakes during the whole analyzed period, and is not in-phase with the variation of Dst index. It seem$\mathrm{s}$ that such enhancement has close relationship with earthquakes.

Comparing the result around $0.1 \mathrm{~Hz}$ with that around $0.01 \mathrm{~Hz}$ in this paper, it is found that the result around $0.1 \mathrm{~Hz}$ have clearly showed significant enhancement before Kashi earthquake and Wenan earthquake. Although the result around $0.01 \mathrm{~Hz}$ also showed similar anomaly before the same earthquakes, there are other enhancement appeared during the analyzed period. According to the skin effect of electromagnetic wave, the $0.01 \mathrm{~Hz}$ waves could come from deeper location of the crust, and go through longer distance to reach geomagnetic observatories on the ground, so it is possible that $0.01 \mathrm{~Hz}$ waves include more underground information than $0.1 \mathrm{~Hz}$ waves.

Although the frequency $0.01 \mathrm{~Hz}$ is thought to be the most useful frequency to detect seismogenic ULF emissions (Hayakawa et al., 2007), the frequency inferred from the focal depth according to the skin effect is also a good candidate to detect the ULF anomaly before earthquakes, which maybe suggest that has more closely relation to earthquake source.

For the earthquake near Kashi on 2 September, 2003, the ULF anomaly is observed almost one month before earthquake. For Wenan earthquake, the ULF anomaly is observed on $27 \sim 30$, June, about a week before earthquake. This ULF lead time seems to be consistent with earlier works (Hattori, 2004).

Hayakawa et al. (2007) indicated that pre-seismic ULF emissions would be detected for earthquakes which roughly satisfy $0.025 R<M-4.5$, where $R$ is epicentral distance. For both earthquakes with ULF anomaly in this paper, the actual epicentral distance is more than twice $(M-4.5) / 0.025$. So for earthquakes which do not satisfy $0.025 R<M-4.5$, ULF anomaly can also be expected.

Because the number of studied events is limited, more cases of ULF geomagnetic anomalies associated with earthquakes are needed to provide convincing conclusion.
Acknowledgements This research was financially supported by the Special Project for Earthquake Research (200708033). The geomagnetic data used in this paper were provided by Kashi and Jinghai observatories in China. The Dst index were downloaded from the website http://swdcdb.kugi.kyoto-u.ac.jp/. Also, the authors would like to thank both reviewers for their helpful advice.

\section{References}

Han D S and Zhang F (2000). Reliability analysis of digital geomagnetic data in SMALL item. Seismological and Geomagnetic Observation and Research 21(5): 1-8 (in Chinese with English abstract).

Fraser-Smith A C, Bernardi A, McGill P R, Ladd M E, Helliwell R A and Villard O G (1990). Low-frequency magnetic field measurements near the epicenter of the $M_{\mathrm{S}} 7.1$ Loma Prieta earthquake. Geophys Res Lett 17(9): $1465-1468$.

Gotoh K, Akinaga Y, Hayakawa M and Hattori K (2002). Principal component analysis of ULF geomagnetic data for Izu islands earthquakes in July 2000. J Atmos Electr 22: $1-12$.

Hattori K (2004). ULF geomagnetic changes associated with large earthquakes. Terrestrial, Atmospheric and Oceanic Sciences 15(3): 329-360.

Hayakawa M, Kawate R, Molchanov O A and Yuomto K (1996). Result of ultra-low-frequency magnetic field measurements during the Guam earthquake of 8 August 1993. Geophys Res Lett 23(3): 241-244.

Hayakawa M, Hattori K and Ohta K (2007). Monitoring of ULF (ultra-low-frequency) geomagnetic variations associated with earthquakes. Sensors 7: 1 108-1 122.

Ida Y, Yang D, Li Q, Sun H and Hayakawa M (2008). Detection of ULF electromagnetic emissions as a precursor to an earthquake in China with an improved polarization analysis. Natural Hazards and Earth System Sciences 8: $775-777$.

Li J H, Li Q, Yang D M, Wang X Z, Hong D Q and He K (2011). Principal component analysis of geomagnetic data for the Panzhihua earthquake $\left(M_{\mathrm{S}} 6.1\right)$ in August 2008. Data Science Journal 10: IAGA130-IAGA138.

Kopytenko Y A, Matiashvili T G, Voronov P M, Kopytenko E A and Molchanov O A (1993). Detection of ultra-lowfrequency emissions connected with the Spitak earthquake and its aftershock activity, based on geomagnetic pulsations data at Dusheti and Vardzia observatories. Phys Earth Planet Interi 77: 85-95. 